\title{
Reciprocal Knowing for Diabetes Literacy among Culturally and Linguistically Diverse Individuals in Australia
}

\author{
Tabassum Ferdous, Central Queensland University, Queensland, \\ Australia \\ Bobby Harreveld, Central Queensland University, Queensland, \\ Australia
}

\begin{abstract}
Health literacy is an important factor in the self management of diabetes. Furthermore, an informed partnership between health professionals and patients-as-consumers that is based on a bothways or reciprocal knowing of each other's culturally constructed understanding of the disease has been found necessary. According to national statistics in Australia, diabetes among migrants has become a priority health issue (Australian Bureau of Statistics [ABS], 2007). Many reasons such as life style, inappropriate health care services, and barriers to accessing ambulatory health care services have been suggested for the increased incidence, complications and mortality rate from diabetes among the overseas born population in Australia (Dixon \& Webbie, 2005). Since diabetes is a lifelong disease, patients require knowledge of both theoretical and practical self-management techniques to manage it in their everyday life. As health literacy has become a very recent concern for the Australian Health service system, and particularly for managing 'diabetes'; health literacy in general and diabetes literacy in particular requires further investigation among culturally and linguistically diverse individuals living with diabetes. This issue is explored through an analysis of adults as learners, multicultural health education and reciprocal knowing in the context of diabetes literacy.
\end{abstract}

Keywords: Adult Learning Process, Diabetes Literacy, Multicultural Health Education, Reciprocal Knowing

\section{Introduction}

TN AUSTRALIA THE high incidence rate of diabetes followed by increased complications among overseas born culturally and linguistically diverse (CALD) individuals compared to the mainstream population has become a health priority for the Australian health service system (Dixon \& Webbie, 2005). In recent years cross-cultural health education and culturally competent health services have been considered as vital elements for recovering from such health status inequality (Colagiuri, Thomas \& Buckley, 2007). Besides, lack of appropriate health literacy has resulted in poor management of diabetes which has further been identified as the basis of this health disparity (Australian Bureau of Statistics $[A B S], 2008)$. In addition to the culturally competent health service provision, health professionals must be mindful that the patients are adult individuals from different cultural backgrounds. Moreover, Kleinman (1978a) identified how patients' cultural background may influence doctor-patient communication. At the same time along with the knowledge about the disease, patients should be aware of Australian health service provision 
which is in most cases different from their home countries (Colagiuri, Thomas \& Buckley, 2007). Thus a 'both way knowing processes' or 'reciprocal knowing' is essential for effective health service provision including improved health literacy.

While it is essential to take improved health literacy into consideration, recommendation has also been made for health care professionals to provide pedagogical conditions conducive to learning for delivering effective culturally appropriate health education (Rudd, Moyekans \& Colton, 1999). In order to understand the effective pedagogic communication that achieves targeted levels of health literacy among culturally diverse individuals, health service providers working with such individuals may benefit from partnership with adult literacy practitioners (Black, Innes \& Chopra, 2008). This article explores the proposition that cross-cultural health education can positively benefit from a multidisciplinary understanding of the concept of 'reciprocal knowing' within an adult learning framework for diabetes education in the Australian context. The proposition is advanced through the analysis of literature in four areas: (1) CALD people living with diabetes; (2) a theoretical framework for cross-cultural health education; (3) a conceptual understanding of health literacy; and (4) issues in the health education of adults as learners living with a chronic disease. It also highlighted the implications for the Australian context identified from the discussion. The article concludes with a summary of key emerging findings.

\section{CALD People Living with Diabetes}

Among all the chronic diseases, diabetes is considered to be one of the high health and cost burden diseases resulting from its untreated long term complications. According to the Access Economics report (2006) for Diabetes Australia (2007), the estimated annual absenteeism from work places cost for Type 2 diabetes was $\$ 53.1$ million in 2005, and the loss from premature death was $\$ 64.7$ million. In Australia, diabetes prevalence and mortality are higher among overseas born migrants, particularly those from the Pacific Islands, SouthEast Asia, China, Middle-East, North Africa, Southern and Eastern Europe (Dixon \& Webbie, 2005). The Australian Institute of Health and Welfare (AIHW) also provided a strong indication that people from culturally and linguistically diverse (CALD) backgrounds were experiencing higher rates of diabetes and diabetes related complications than that of Australian-born population (Dixon \& Webbie, 2005), However, Diabetes Australia claims that an appropriate diabetes self-management strategy can not only minimise the development of complications and disease progression, it can also significantly reduce the burden of the effect of diabetes on a country's health system and its economy (Diabetes Australia, 2009).

At the state level, Queensland Health (2002) developed a Health outcomes plan for Diabetes 2000-2004 which covered diabetes primary prevention, early detection and management. As a part of this plan in 2000, Queensland Health conducted a chronic disease survey to investigate the risk factors for all individuals with diabetes living in Queensland. Significantly, this chronic disease survey excluded the people who did not speak English sufficiently for an interview to be conducted. Those who were CALD and who could speak English well enough to interview were included (Queensland Health, 2002). Language barriers and the lack of a culturally competent health service have been widely recognized by National Health Priority Action Council (NHPAC) (2005) as barrier to ensure appropriate health services for CALD people. However, such exclusion from a chronic disease survey had deprived the health service providers from valuable information about how some CALD people manage 
their diabetes, whether or not they could follow the treatment regimen and what was their level of knowledge about diabetes.

Living with chronic disease for the affected individuals and for their families often means physical and psychological difficulties, socio-economic problems and reduced quality of life (Department of Health UK, 2001). For migrant people this physical condition becomes more critical when interwoven with other settlement related issues in a new country. Traditionally these problems have not been dealt with by the formal and/or informal adult community education sector, health care providers or the employment services. As stated in the publication 'Expert Patient: A New approach to Chronic Disease Management for the 21st Century' (Department of Health UK, 2001), most attention was given to the technical aspects of the disease management rather social and emotional consequences of the disease. Furthermore studies indicated that there is less satisfaction, less compliance and more misunderstanding when doctors and patients are sharing different cultural or ethnic backgrounds (Harmsen, Meeuwesen, van Wieringen, Bensen \& Brijinzeels, 2003 \& Laveist, Nuru-Jeter, 2002). Therefore, it is necessary to emphasize the importance of contextual understanding of a target population before delivering programs for sharing health related knowledge (Jacobson, Butterill \& Goering, 2003). Very recently in 2008-2009 Queensland Health recognised the need for developing a culturally competent health service and delivery to meet the need of increasing level of cultural diversity in the Queensland population (Queensland Health, 2010).

\section{Cross-cultural Health Education}

\section{One-way Knowledge Transfer}

While developed countries are having a liberal multicultural perspective in their health care systems, health education for adults from culturally and linguistically diverse (CALD) backgrounds has focused on a one-way knowledge transfer in which a dominant language (for example, English) and a dominant health care culture (e.g. Australian or British or American) are simply translated for the recipients (National Council for Interpreting in Health Care [NCIHC], 2009). Evidence of this can be seen in the multi-lingual brochures produced by government departments and websites such as Diabetes Australia and Cancer Council Australia that provide information for 'multicultural audiences' (Diabetes Australia, 2009 \& Cancer Council Victoria, 2009). This means English is translated and then 'given' to the recipient without consideration of other cultural factors that may be impacting their diabetes self-management. It is up to the health care consumer to make sense of this information.

The verbal and practical instructions provided by the health professionals such as doctors, nurses and health educators may not be understandable to the patients or they may simply not agree with the information provided (Kleinman, Eisenberg \& Good, 2006). Usually they do not express their concern to the health professionals and this may be due to their low literacy which could be accompanied by feeling of shame (Rudd, Moyekans \& Colton, 1999). Moreover, health professionals may not take into account that there is a discrepancy between health professionals' biomedical knowledge construction and peoples' knowledge and perception of disease (Kleinman et. al., 2006). To date no such system or service is in place to assess patients' understandings and compliance to the regimen prescribed. Therefore, despite 
effective action of the prescribed remedies, patient may not be able to self-manage effectively (Kleinman et.al, 2006). Hence, this is considered as a one-way knowledge transfer. This suggests that it is necessary to consider Klienman's (1978a) Explanatory Model for crosscultural health education which is still relevant even though it was proposed way back in late 1970's. It still has much to offer understanding of the ways in which a patient's cultural background may influence doctor-patient communication.

\section{Explanatory Model by Kleinman}

To understand how a patient's cultural background may influence doctor-patient communication, Klienman (1978) has proposed the idea of this Explanatory Model (EM) represented in Figure 1 which depicts the internal structure of a health care system. Through the following Model (Figure1), Kleinman (1978b) offered the health care system as a cultural system where health, illness and health care-related aspects and societies are articulated together (Kleinman, 1978b). Therefore, he claimed that as part of a same cultural system, illness, health and health care should be comprehended in relation to each other. According to Kleinman (1978b) there are three social arenas in most of the health care systems: popular, professional and folk arenas. In his article he claimed that both in the western and nonwestern society's 70-90\% illness (not disease) are managed by popular arena of individual, family, social and community based support. The reason for this could be the maximum concordance between socio-cultural reality of patients and healer.

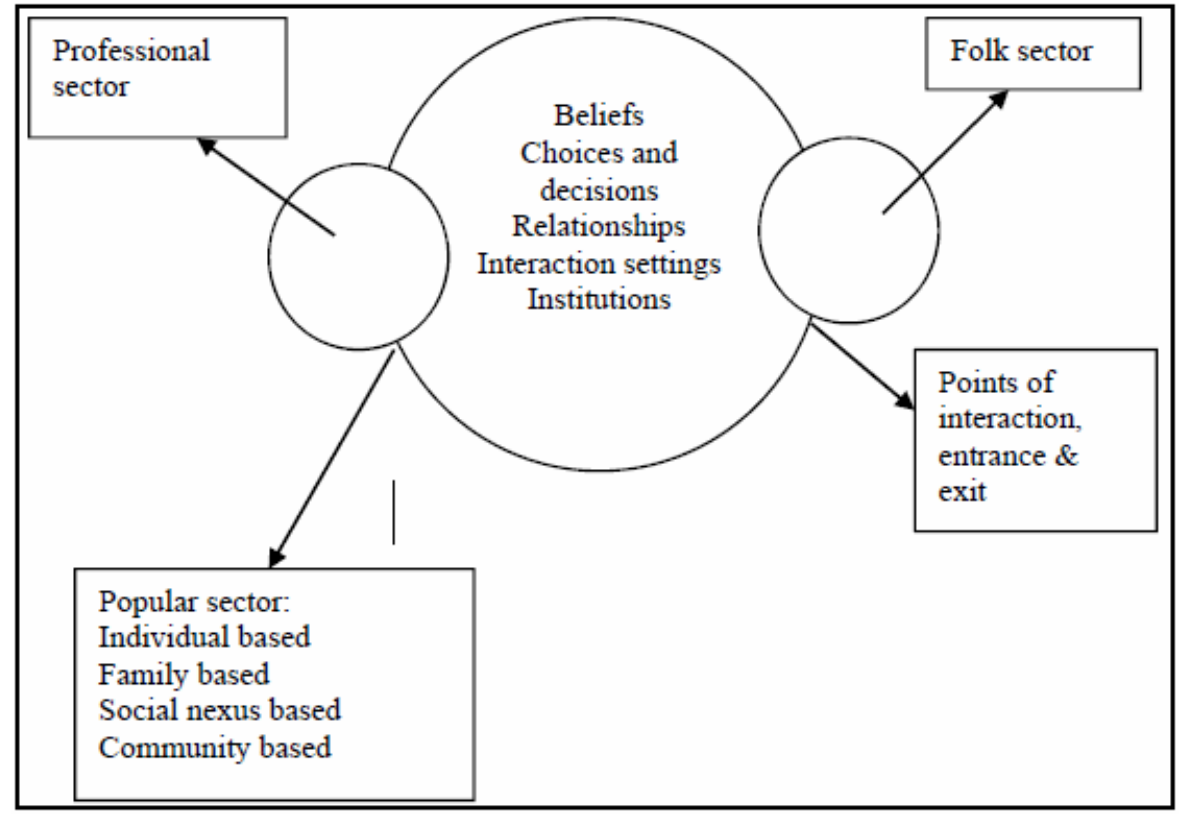

Figure 1: Health Care System-internal Structure (Adapted from Kleinman 1978 p.86)

In this model 'illness' and 'disease' do not mean the same. According to Kleinman et al. (2006): 
disease in the western medical paradigm is malfunctioning or maladaptation of biologic and psychophysiologic process in the individual; whereas 'illness' represents personal, interpersonal and cultural reaction to disease or discomfort. (p.141)

Since illness is constructed by patients' perception, experience, explanation of sickness specific to the social position they occupy, there will be discrepancies between patients' and doctors' Explanatory Models (EMs). This EM is defined as "the notions about an episode of sickness and treatment that are employed by all those engaged in the clinical process" (Klienman, 1983, p.539). Patients' EMs are influenced by personality and cultural factors, yet doctors' EMs are mostly based on their biomedical perspective (Klienman, 1983) results in gaps in doctor-patient communication. Therefore, the dilemma and issues that have given rise to this paper are clearly located in the nexus between EMs of health professionals and EMs of patient and the implication of reciprocal knowledge for cross-cultural diabetes education as a consequence.

\section{Reciprocal Knowing}

In the context of health education for CALD people who are living with chronic diseases, the literature suggests that there is a lack of reciprocal knowing - a two-ways knowledge. It was also claimed that "minority groups tend to know more about the majority groups than vice versa" (Ojanlatva, Vandenbussche, \& Heldt et al., 1997, p.171). Here the authors referred to the diverse immigrant groups as minority and main stream residents as majority. This reciprocal knowing was also identified by Chachkes and Christ (1996) as fundamental to effective health education among people living in culturally and linguistically diverse communities. It is often not understood that an individual's culture can be immensely different and that these cultural differences may manifest themselves very subtly. (Chachkes \& Christ, 1996). After a decade still the same is being claimed in the research publications. As in 2006 , considering the fact that more than $18 \%$ of the Netherland's population are from different ethnic and cultural backgrounds, Schouten and Meeuwesen (2006) tried to gain more insight in terms of effective and satisfying doctor-patient relationship. In a literature review of 'Cultural difference in medical communication' conducted by the authors, major differences in doctor-patient communication were revealed as consequences of patient's ethnic background. In the review, five key predictors of culture related communication problems were identified:

(1) cultural difference (according to Klienman's explanatory model) of health \& illness,

(2) differences in cultural values, (3) cultural differences in patient's preferences for doctor-patient relationship, (4) racism/perceptual biases, and (5) linguistic barriers (Schouten \& Meeuwesen, 2006, p.21).

Therefore, it is an enormous challenge for health professionals to educate patients from a wide variety of language, cultural and educational backgrounds. In the Australian health system, the concept of a both-ways knowing is not new as claimed by McGrath, Holewa, Ogilvie, Rayner and Patton (2006) in regards to health service provision for Aboriginal people. Their paper advocates for cross-cultural two way educational exchange which enable medical and nursing personnel to improve their perception of indigenous people's view of 
cancer and at the same time enable Indigenous people to learn more about prevention and treatment of cancer from a biomedical perspective. A qualitative study by Kokanovic and Manderson (2006) conducted on the Australian immigrant in Victoria found that not only the patients found difficulties in understanding and comprehending the information provided for managing their disease but the doctors also experienced problem in regards to patients' behaviour change, compliance to treatment regimen and establishing relationship with patients.

Additionally, low general and/or health literacy among patients has been a concern for the health educators. In 2001, there were 3.5 million overseas born people living in Australia whose first language was not English. Forty-five percent (45\%) of those people had poor English language skills and $25 \%$ of them had low literacy in their first language (Keleher \& Hagger, 2007). This situation is high lightened by the frustration expressed from Vietnamese General Practitioners for their inability to educate a high number of diabetic individuals for preventing complications even being a health professional from same cultural and linguistic background. This indicates that along with cultural issue something more need to be addressed like the issue of low health literacy. It has been a concern that people who took the literature provided to them did not ever mention that they could not read it (Cameron, 2002), which could be due to the embarrassment that often goes along with low literacy. This suggests to pay attention to the issue of a potentially low literacy cum low health literacy among this targeted CALD population A limited health literacy was found to be associated with poor self-care for the chronic diseases like Asthma, Acute Immune Deficiency Syndrome (AIDS), Hypertension and Diabetes (Kim \& Love, 2004; Kalichman, Ramachandran \& Catz, 1999 and Williams, Baker, Honig, Lee \& Nowlan, 1998).

Health information is an essential resource for patients to understand the disease and to manage their health conditions. Levin-Zamir and Peterberg (2001) recommended promoting health literacy as the central strategy for improving self-management. The researchers found that it was essential for health care providers to promote informed decision making and to facilitate the improvement of personal capacity. The personal capacity is required for applying control over factors which establish health and produce healthy outcome.To explore this latest issue of health literacy, in the following sections this article has provided a brief discussion in terms of its definition, component and criticism followed by health literacy in Australia and diabetes literacy in the context of CALD individuals with diabetes.

\section{Health Literacy}

The World Health Organization has defined Health Literacy (HL) as "the cognitive and social skills which determine the motivation and ability of individuals to gain access to, understand, and use information in ways which promote and maintain good health" (WHO, 1998, p.10). Again according to the USA Department of Health and Human Services (2000b) health literacy is "the degree to which individuals have the capacity to obtain, process and understand basic health information and services needed to make appropriate health decisions". Later this health literacy definition has evolved to include the notion of 'interactive health literacy' (IHL) and 'critical health literacy' (CHL). Interactive health literacy is the development of interpersonal and social skills that encourage people to change their health behaviour and critical health literacy is the ability of a person and a community to address the systematic factors that affect health (Nutbeam, 1998; Kickbush, 2002). Levin-Zamir (2001) identified these three different types of health literacy - functional, interactive and critical health literacy. 
Again, Nutbeam (2000) proposed a hierarchical model of health literacy that includes three levels: functional, communicative and critical literacy. Level I is called functional literacy which was considered as the basic level of reading and writing skill that allows a person to function effectively in everyday situations for managing a disease. For example, this level is needed to read the name of medicine, direction for using and measure the amount of medicine, reading information brochure or appointment card. Level II is known as 'interactive' or 'communicative' literacy which was defined as the advanced skill that let someone to extract information and meaning from different forms of communication and make the information effective to changing circumstances. This interactive literacy is based on a solid foundation of functional literacy and can be advanced through to the next level named 'critical literacy' (Nutbeam, 2008). Hence, these definitions acknowledge the fact that health literacy operates within a 'complex group of reading, listening, analytical and decision making skills' and is dependent upon 'the ability to apply these skills to health situations' (US Department of Health and Human Services, 2000a, para 2).

\section{Criticism - Health Literacy}

However, Smylie, Williams and Cooper (2006) were critical of health literacy definition which considered literacy as a person's ability to read and understand medical information yet, the definition ignore the difference between western socio-cultural context and sociocultural realities of an individual. Their criticism acknowledges the fact that in order to improve health outcome, health literacy should not stand alone as the general literacy and numeracy skill, it should also be integrated with the socio-cultural context where the patients belong to as claimed by the authors that "Litearcy is constructed and enacted within social, cultural and political contexts" (Smylie, Williams \& Cooper, 2006, p.sp.22).

\section{Health Literacy in Australia}

Health literacy was incorporated in Australia's health oriented goals in mid-1990s (Keleher \& Hagger, 2007). However, almost a decade after in 2006, the Australian Bureau of Statistics conducted the first national health literacy survey as part of the Adult Literacy and Life skills Survey [ALLS] (ABS, 2008). This health literacy survey demonstrated the extent of poor health literacy in Australia and indicated that people with the poorest levels were generally older, lacking formal education, un-employed or their first language was not English. In the ALLS, health literacy was divided in to four domains: prose, document, numeracy and problem-solving domains. A brief description of the four domains is:

1. Prose literacy: the ability to understand and use information from various kinds of narrative texts, including texts from newspapers, magazines and brochures.

2. Document literacy: the knowledge and skills required to locate and use information contained in various formats including job applications, payroll forms, transportation schedules, maps, tables and charts.

3. Numeracy: the knowledge and skills required to effectively manage and respond to the mathematical demands of diverse situations.

4. Problem solving: goal-directed thinking and action in situations for which no routine solution is available (ABS, 2008, p.8). 
For each literacy domain, proficiency was measured on a scale ranging from 0 to 500 points. In regards to health literacy, the score ranges for each level of proficiency were: Level 1: 0225, Level 2: 226-275, Level 3: 276-325, Level 4: 326-375, Level 5: 376-500 (ABS, 2008). Of all overseas born people mainly in a non-English speaking country, only $26 \%$ achieved Level 3 or above compared to those born in Australia (44\%). Whereas $46 \%$ of people born outside of Australia in mainly English speaking countries scored at Level 3 or above on the ALLS health literacy scale. Language and literacy barriers within some CALD groups were identified as a barrier to accessing services. Often these people need to use friends and relatives as interpreters during consultations with health professionals (Colagiuri, Thomas \& Buckley, 2007). Though research into chronic disease self-management with CALD communities including health literacy is in progress; however, there is a dearth of breadth in research leading to an inconsistent knowledge base (Keleher \& Hagger, 2007, p.24).

\section{Diabetes Literacy}

The concept of 'diabetes literacy' is relatively new and drawing on a recent operational definition of health literacy. Black, Innes and Chopra (2008) defined it as, "the skills and competences to comprehend, evaluate and use information to make informed choices about the risks, prevention and management of diabetes" (p.1). Black, Innes and Chopra (2008) initiated a partnership approach between health and adult literacy sectors in the delivery of diabetes literacy program among CALD groups in New South Wales, Australia. The researchers claimed that the idea of this partnership program evolved due to the presence of commonalities between values and concepts of both health and adult literacy. Both these sectors are focusing on social determinants of health and social practices concepts of literacy. As claimed by the authors this small scale pilot project contributed in a number of ways: it has provided a place for 'diabetes literacy' in the health and education sectors, an effective intervention model for providing diabetes literacy at the local level, and an 'integrated literacy concept' where health and adult literacy sector can work together.

Kim and Love (2004) conducted a study to assess the association of health literacy with self-management behavior in patients with diabetes. The study participants were enrolled in diabetes education classes at the Hospital of University of Pennsylvania. The research suggested that health literacy was independently related to patients' diabetes knowledge and to improving self-management of diabetes for patients with limited and adequate health literacy at the base line. Additionally, to develop effective patient education and improve patients' diabetic control and own complications, educational strategies also need to consider patients' self-care skills. (Tang, Pang, Chan, Yeung \& Yeung, 2008). The researchers remarked that exploring a patient's HL levels may provide a better understanding of the patient's potential barriers to self-management of disease and health promoting behaviors (Ishikawa, Takeuchi \& Yano, 2008). Carolan, Steele and Margetts (2010) conducted a study among 143 multiethnic pregnant women in Australia with diabetes to examine their attitude and belief about gestational diabetes. The authors suggested that non-Caucasian women with lower education, lower health literacy and a lower understanding of gestational diabetes as a serious condition, may be at risk of poor self-management of diabetes. On the other hand, Keleher and Hagger (2007) pointed out that literacy skills are not a definite predictor of the effectiveness of health education. Therefore, according to the notion of Kleinman's (1978a $\&$ b, 1983) explanatory model, to acquire better health literacy level among CALD patients, 
an interactive learning process is required between patients and health professionals. As suggested by Chachkes and Christ (1996, p.20) "the professionals needs to learn about and from the patients' culture and health beliefs, as well as to teach and inform about dominant culture ways". Furthermore, a one-way knowledge transfer does not reflect the whole pedagogic process of adult learning.

\section{Health Education}

\section{Adult Learners with Chronic Disease}

Adult-learning is a complex process, and the complexity is exacerbated when adults are positioned as 'patients' who have to acquire knowledge of a chronic disease and furthermore have to learn how to manage it themselves for the rest of their lives, albeit with assistance from health professionals. As noted by Walker (1999), people with diabetes are compelled to undertake of study of diabetes management; it is not like participating other adult education. Additionally, the author reminded that diabetes education is not only learning and acquiring information but also requires a change in patients' behaviour (Walker, 1999). Again, health professionals or health educators need to be mindful that learning process of children and that of adult are two different processes (Knowls, 1970). The differences in adult learners are in regards to their previous experience, motivation to change, level of engagement and practical application of the learning (Russell, 2006). Here the processes of adult-learning and patient education are intimately related.

In a discussion paper of 'Cross cultural issues in patient education', Chachkes and Christ (1996) suggested that for such cases effective education was required in which the "whole pedagogic process be altered to take into account cultural and language barriers and resistances that impede the learning process" (p.15). Though this paper by Chachkes and Christ (1996) published more than a decade ago, still their recommendation is being followed; as suggested by Povlsen and Ringsber $(2009,2008)$ that patients with diabetes and parents of diabetic children with an immigrant background are likely to require special pedagogic, psychological and social support to learn and to adapt with the management of a chronic disease. Further to the suggestion of Chachkes and Christ (1996), Walker (1999) proposed adult learner characteristics for diabetes education which incorporated patient's literacy level, ageing issues, gender, cultural backgrounds, personal knowledge and beliefs about the disease, autonomy and psychological profile. These individual characteristics again may be attributed to social class, financial, educational and religious differences within patients from one country.

Even difference in geographical location may cause variation in cultural themes among people from the same religion and language backgrounds. Cultural assimilation is another factor that may influence the health education and learning process among migrant individuals (Chachkes \& Christ, 1996). For example, it may be different for an individual with diabetes who migrated from the Middle-East or Asia to follow the diet plan and menu advised by diabetic educators or dietician unless they assimilate them-selves with western food and lifestyle. Additionally, the current, newer and complex treatments accompanied with technologies may perhaps be a challenge for some of the patients to follow on their own at home. Hence, it becomes a superimposed and enormous burden for patients who are from linguistic and cultural backgrounds which are different from those of the instructing health professionals (e.g. doctors, nurses, allied health professionals and so on). 


\section{Implications in the Australian Context}

Australia has been known as one of the most culturally and linguistically diverse countries in the world with one in three residents born overseas (Colagiuri, Thomas \& Buckley, 2007), yet it experiences a considerable amount of barriers for delivering effective and equitable health care services (Von, Thomas \& Colagiuri, 2002). Moreover, a high prevalence of diabetes has been identified among certain cultural and ethnic communities such as Asian, African, Middle Eastern, Pacific Islanders and Eastern European (AIHW, 2006). Factors such as genetics, immigration, socio-economic and socio-cultural factors were suggested to be responsible for such a high prevalence of diabetes among CALD communities (Colagiuri, Thomas \& Buckley, 2007). In addition to its complexity, progressive nature and requirement of life long costly treatment, eventually diabetes may affects the productive years of a person's life (King, Aubert \& Herman, 1998). Therefore, Australian experts advocated that it was essential to generate recommendations specific to diabetes and other chronic disease risk reduction interventions among CALD communities in Australia (Eigenmann \& Colagiuri, 2007).

'Culture, Health and Literacy' a guide to health education materials for adult with limited English literacy skill was developed by World Education (USA) back in 1999 which proposed for health care practitioners working with patients with limited English literacy or adult literacy practitioners. The health education materials particularly targeted teachers of English for speakers of other language (ESOL), who want to incorporate health topics into their curriculum (McKinney \& Kurtz-Rossi, 2000). In Australia after more than a decade, health literacy has just started to be noticed. This late initiative is evident by the National health literacy survey in 2006 (ABS, 2008) and the 'Diabetes literacy' project in New South Wales initiated by Black, Innes and Chopra in 2008. Along with the recommendation from a small scale Australian project conducted by Black, Innes and Chopra (2008), the health service providers and policy makers in Australia have examples and guide lines from the USA and Canada in hand for implication. At the same time more multidisciplinary research can be conducted between health and education sector to evaluate the effectiveness of those existing programs in Australian context.

\section{Conclusion}

This focused analysis of salient literature from the fields of health education and adult learning has found a traditional one-way knowledge transfer from health practitioner is problematical for CALD adults living with diabetes. This finding is supported with evidence of the diabetes related health disparities between CALD individuals and Australians of Western origin (AIHW, 2006). A consideration of Kleinman's (1978 a \& b, 1983) explanatory model of disease and illness has concluded that reciprocal or 'both-ways' knowing is essential between health service providers and CALD patients. However, Kleinman's explanatory model does not take account of the role of patient/s' literacy in such reciprocal knowledge transactions between practitioners and patients. The concept of illness among such patients and their corresponding health literacy constructions occur in a range of social, cultural and political contexts (Smylie, Wiliams \& Cooper, 2006). Both the adult patients and health practitioners will benefit from communication predicated upon a reciprocal knowing of each other's cultural and linguistic constructions of health and illness. 
The analysis of literature in the self-management of diabetes and implications for reciprocal knowing among health service providers and the patients suggests that it is not a standalone simple issue to consider. Rather, it has emerged as a complex multi-faceted issue consisting of: (a) one-way knowledge transfer in which health education is traditionally provided; (b) Kleinman's (1978 a \& b, 1983) explanatory model to identify differences of socio-cultural reality of disease between doctor and patient; (c) a reciprocal knowing with the need of both health professional and patients to know each other; (d) the issue of health literacy among CALD people; and finally (e) the pedagogy of adult learning in which the characteristics of the learners need to be considered. Accordingly, the need for reciprocal knowing and the adoption of adult learning pedagogy for delivering cross-cultural health education are worthy of further research if improved health literacy for diabetes self-management among CALD Australians is to be achieved. 


\section{References}

Australian Bureau of Statistics (ABS). (2008). Health literacy, Australia, 2006. (Cat. No. 4233.0) Canberra, ACT, Australia.

Australian Bureau of Statistics (ABS). (2007). 1301.0-Year Book Australia, International migration. Viewed May 10, 2007 from http://www.abs.gov.au/AUSSTATS/abs@.nsf/DetailsPage/ 1301.02007? OpenDocument

Access Economics. (2006). The Economics Costs of Obesity; Report by Access Economics to Diabetes Australia, October 2006.

Australian Institute of Health and Welfare (AIHW). (2006). Australia's health 2006. (Cat. no. AUS 73). Canberra: AIHW.

Black, S., Innes, C., \& Chopra, M. (2008). Diabetes Literacy: A partnership approach to educating culturally and linguistically diverse people about the risks and prevention of type 2 diabetes. NSW: TAFE NSW Northern Sydney Institute and Northern Sydney Central Coast Area Health Service.

Cameron, T. (2002). Break down the barriers. Diabetes Australia Conquest Magazine Spring, 4-5.

Carolan, M.C., Steele, C., \& Margetts, H. (2010). Attitudes towards Gestational Diabetes among a multi-ethnic cohort in Australia. Journal of Clinical Nursing, 19 (17-18), 2446-2453.

Cancer Council Victoria. (2009). CALD, Multilingual cancer information. Viewed July 16, 2009, from http://www.cancervic.org.au/other_languages

Chachkes, E. \& Christ, G. (1996). Cross cultural issues in patient education. Patient Education and Counseling, 27, 13-21.

Colagiuri R., Thomas, M. \& Buckley, A. (2007). Preventing type 2 Diabetes in Culturally and Linguistically Diverse Communities In NSW, Sydney, NSW Department of Health.

Department of Health UK. (2001). The Expert Patient: A New Approach to Chronic Disease Management for the 21st century, Viewed 1 June 2007, from http://www.dh.gov.uk/en/Publicationsandstatistics/Publications/PublicationsPolicyAndGuidance/DH_40.

Diabetes Australia. (2007). Cross Cultural Communication Program. Viewed June 1, 2007, from http://www.diabetesaustralia.com.au/cccp/index.htm

Diabetes UK. (2009). Other Languages. Viewed July 16, 2009, from http://www.diabetes.org.uk/ Other languages/

Diabetes Australia. (2009). For Health Professionals, Viewed August 22, 2009, from http://www.diabetesaustralia.com.au/For-Health-Professionals/Resources/

Dixon, T., \& Webbie, K. (2005). Diabetes related deaths 2001-2003 (No. 32). Canberra: Australian Institute of Health and Welfare (AIHW).

Eigenmann, C. A. \& Colagiuri, R. A. (2009). National consensus on outcomes and indicators for diabetes patient education. Diabetic Medicine. 26(4), 442-446.

Harmsen, H., Meeuwesen, L., van Wieringen, J., Bernsen, R., \& Bruijnzeels, M. (2003). When cultures meet in general practice: intercultural differences between GPs and parents of child patients. Patient Education and Counseling, 51(2), 99-106.

Ishikawa, H., Takeuchi, T., \& Yano, E. (2008). Measuring functional, communicative, and critical health literacy among diabetes patients. Diabetes Care, 31(5), 874-879.

Jacobson, N., Butterill, D., \& Goering, P. (2003). Development of a framework for knowledge translation: understanding user context. Journal of Health Service Research Policy, 8(2), 94-99.

Kalichman, S. C., Ramachandran, B., \& Catz, S. (1999). Adherence to combination antiretroviral therapies in HIV seropositive men and women of low health literacy. Journal of General Internal Medicine, 14, 267-273.

Keleher, H. \& Hagger, V. (2007). Health literacy in primary health care. Accepted for publication, Special Issue on "Comparative Approaches to Primary Health Care: Key Lessons for Australia's Primary Health Care Policy-Making". Australian Journal of Primary Health. August 2007. 
Kickbusch, I. (2002). Health literacy: a search for new categories. Health Promotion International, $17(1), 1-2$.

Kim, S., Love, F., Quistberg, D. A., \& Shea, J. A. (2004). Association of Health Literacy with SelfManagement Behavior in Patients with Diabetes. Diabetes Care, 27(12), 2980-2982.

King, H., Aubert, R. E. \& Herman, W.H. (1998). Global burden of diabetes, 1995-2025: prevalence, numerical estimates, and projections. Diabetes Care, 21(9), 1414-1431.

Kleinman, A. (1978a). Clinical relevance of anthropological and cross-cultural research: concepts and strategies. American Journal of Psychiatry, 135(4), 427-431.

Kleinman, A. (1978b). Concepts and a model for the comparison of medical systems as cultural systems. Social Science and Medicine, 12, 85-93.

Kleinman, A. (1983). The cultural meanings and social uses of illness. Journal of Family Practice, $16,539-545$.

Kleinman, A., Eisenberg, L., \& Good, B. (2006). Culture, Illness, and Care: Clinical Lessons from Anthropologic and Cross-Cultural Research. Focus, 4(1), 140-149.

Knowels, M. (1970). Andragogy: an emerging technology for adult learning. In R. Edwards, A. Hanson \& P. Ragatt (Eds.), Adult Learners, Education and Training 1: Boundaries of Adult Learning. London, Routledge.

Kokanovic, R. \& Manderson, L. (2006). Social support and self-management of type 2 diabetes among immigrant Australian women. Chronic Illness, 2(4), 201-303.

Laveist, T. A., \& Nuru-Jeter, A. (2002). Is Doctor-patient Race Concordance Associated with Greater Satisfaction with Care?. Journal of Health \& Social Behaviour, 43(3), 296-306.

Levin-Zamir, D., \& Peterburg, Y. (2001). Health literacy in health systems: perspectives on patient self-management in Israel. Health Promotion International, 16(1), 87-94.

McGrath, P., Holewa, H., Ogilvie, K., Rayner, R. \& Patton, M. A. (2006). Insights on Aboriginal peoples' views of cancer in Australia. Contemporary nurse: a journal for the Australian nursing profession, 22, 240-254.

McKinney, J. \& Kurtz-Rossi, S. (2000). Culture, Health and Literacy: A guide to Health education materials for adults with limited English Literacy Skills, Developed by World Education in collaboration with the National Institute for Literacy.

National Health Priority Action Council (NHPAC). (2005). National service improvement framework for diabetes, Australian Government Department of Health and Ageing, Canberra, viewed from http://www.health.gov.au/internet/main/publishing.nsf/Content/pq-ncds-diabetes

National Council in Interpreting of Health Care (NCIHC). (2009).Viewed September 12, 2009, from http://www.ncihc.org/

Nutbeam, D. (1998). Health Promotion Glossary. Health Promotion International, 13(4), 349-364.

Nutbeam, D. (2000). Health literacy as a public health goal: a challenge for contemporary health education and communication strategies into the $21^{\text {st }}$ Century. Health Promotion International, $15,259-267$.

Nutbeam, D. (2008). The evolving concept of health literacy. Social Science \& Medicine, 67(12), 2072-2078.

Ojanlatva, A., Vandenbussche, C., Heldt, H., Horte, A., Häggblom, T.-M., Kero, J., Kähkönen, J., Möttönen, M., Saraste, A. \& Turunen, T. (1997). The use of problem-based learning in dealing with cultural minority groups. Patient Education and Counseling, 31, 171-176.

Povlsen, L., \& Ringsberg, K. C. (2008). Learning to live with type 1 diabetes from the perspective of young non-western immigrants in Denmark. Journal of Clinical Nursing, 17(11C), 300-309.

Povlsen, L., \& Ringsberg, K. C. (2009). Learning to live with a child with diabetes-Problems related to immigration and cross-cultural diabetes care. Scandinavian Journal of Caring Sciences, 23(3), 482-489.

Queensland Health. (2002). Chronic Diseases Survey: Diabetes Prevalence and Management Report. Viewed December 2002, from http://www.health.qld.gov.au/hic/Diabetes_report.pdf 
Queensland Health. (2010). Multicultural Health. Viewed August, 2010, from http://www.health/ qld.gov.au/multicultural/health_workers/ccld-strategy.pdf

Rudd, R., Moeykens, B. \& Colton, T. (1999). Health and Literacy: A Review of Medical and Public Health Literature. In: Comings J, Garners B, Smith C (Eds), Annual Review of Adult Learning and Literacy (Chap. Five), Viewed from http://www.ncsall.net/?id=771\&pid=522

Russell, S. S. (2006). Continuing Education: An Overview of Adult-Learning Process. Urologic Nursing, . 26, 349-352.

Schouten, B. C. \& Meeuwesen, L. (2006). Cultural differences in medical communication: A review of the literature. Patient Education and Counseling, 64, 21-34.

Smylie, J., Williams, L., \& Cooper, N. (2006). Culture-based literature and Aboriginal health. Canadian Journal of Public Health, 97(2), S21-S25.

Tang, Y.H., Pang, S.M., Chan, M.F., Yeung, G.S., \& Yeung, V.T. (2008). Health literacy, complication awareness, and diabetic control in patients with type 2 diabetes mellitus. Journal of Advance Nursing, 62, 74-83.

U.S. Department of Health and Human Services (a). (2000). Healthy People 2010. $2^{\text {nd }}$ ed. With Understanding and Improving Health and Objectives for Improving Health. $2^{\text {nd }}$ vol. Washington, DC: U.S. Government Printing Office.

U.S. Department of Health and Human Service (b). (2000). National network of libraries of medicine Viewed July, 2010, from http://nnlm.gov/outreach/consumer/hlthlit.html

Von Hofe, B., Thomas, M., Colagiuri, R. (2002). A Systematic Review of Issues Impacting on Health Care for Culturally Diverse Groups using Diabetes as a Model. (Audio Visual) Sydney, Australian Centre for Diabetes Strategies \& Multicultural Health Unit.

Walker, E.A. (1999). Characteristics of the adult learner. Diabetes Educator, 25, 16-24.

Williams, M. V., Baker, D. W., Honig, E. G., Lee, T. M., \& Nowlan, A. (1998). Inadequate health literacy is a barrier to asthma knowledge and self-care. Chest, 114, 1008-1015.

World Health Organisation (WHO). (1998). Health Promotion Glossary, Division of Health Promotion, Education and Communications (HPR), Health Education and Health Promotion Unit (HEP), Viewed August, 2010, from WHO/HPR/HEP/98.1 viewed from http://www.who.int/ hpr/NPH/docs/hp_glossary_en.pdf

\section{About the Authors}

\section{Tabassum Ferdous}

I have got a bachelor degree in Medicine and Surgery and practiced as a doctor for 6 years in Bangladesh. Then after migrating to Australia I started to study Public Health and obtained a degree of post-graduate diploma in Public Health from University of Queensland followed by Masters by research in Health Science from CQUniversity. The focus of my research for masters degree was on formal health education for mammography among non-English speaking background women in Australia. Currently I am doing my $\mathrm{PhD}$ at CQUniversity on health education for self-management of diabetes among culturally and linguistically diverse individuals in regional Australia. During my study period of masters I was actively involved with different academic and community related positions such as a project officer, research assistant,and tutor for indigenous nursing and public health students. 
Dr. Bobby Harreveld

Bobby is currently researching relationships among policy and practice in education and training innovations; and advancing the conceptual framing of co-ordinations of power relations and resilience through professional identities as an expression of, and response to, changing conditions of work. In particular, she is interested in the impacts of cross-sectoral, inter-systemic education and training reform agenda enacted at multiple levels in organisations and communities. As well as coordinating a postgraduate coursework masters program, Bobby teaches undergraduate students and supervises doctoral research higher degree students. 



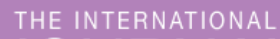

\section{Editors}

Bill Cope, University of Illinois, Urbana-Champaign, USA.

Kristen Harrison, University of Illinois, Urbana-Champaign, USA.

\section{Editorial Advisory Board}

Graham Basten, School of Allied Health Sciences, De Montfort University, UK

Karen Chapman-Novakofski, Department of Food Science \& Human Nutrition and

Department of Internal Medicine, University of Illinois, Urbana-Champaign, USA

Kristen Harrison, Department of Communication, University of Illinois, Urbana-Champaign, USA

Steven S. Kuwahara, Principal Consultant, GXP BioTechnology, USA

Marek Malecki, Genetics, Genomics, and Gene Therapy, Western University of Health Sciences, USA

David Peters, Editor in Chief, Journal of Holistic Healthcare, School of Life Sciences, University of Westminster, UK

Darlene Sredl, College of Nursing, University of Missouri St. Louis, USA

Please visit the Journal website at http://healthandsociety.com/journal/ for further information about the Journal or to subscribe. 


\section{The Health, Wellness and Society Community}

This knowledge community is brought together by a common concern for learning and an interest to explore new educational possibilities. The community interacts through an innovative, annual face-to-face conference, as well as year-round virtual relationships in a weblog, peer reviewed journal and book imprint - exploring the affordances of the new digital media. Members of this knowledge community include academics, teachers, administrators, policy makers and other education practitioners.

\section{Conference}

Members of the Health, Wellness and Society Community meet at The International Conference on Health Wellness and Society, held annually in different locations around the world, each selected for the particular role Health and Wellness is playing in social, cultural and economic change. The Inaugural Conference was held at University of California Berkeley, USA in 2011 and in 2012 the Conference will be at University Center, Chicago, USA.

Our community members and first time attendees come from all corners of the globe. Intellectually, our interests span the breath of the field of health and social sciences. The Conference is a site of critical reflection, both by leaders in the field and emerging scholars and teachers. Those unable to attend the Conference may opt for virtual participation in which community members can either or both submit a video or slide presentation with voice-over, or simply submit a paper for peer review and possible publication in the Journal.

Online presentations can be viewed on YouTube.

\section{Publishing}

The Health, Wellness and Society Community enables members to publish through three mediums.

First, by participating in the Health, Wellness and Society, community members can enter a world of journal publication unlike the traditional academic publishing forums $-\mathrm{a}$ result of the responsive, non-hierarchical and constructive nature of the peer review process. The International Journal of Health, Wellness and Society provides a framework for double-blind peer review, enabling authors to publish into an academic journal of the highest standard.

The second publication medium is through the book series Health and Society, publishing cutting edge books on education in print and electronic formats. Publication proposals and manuscript submissions are welcome.

The third major publishing medium is our news blog, constantly publishing short news updates from the International Health, Wellness and Society Community, as well as major developments in the field of health and social sciences. You can also join this conversation at Facebook and Twitter or subscribe to our email Newsletter. 


\section{Common Ground Publishing Journals}

\begin{tabular}{|c|c|}
\hline $\begin{array}{l}\text { AGING } \\
\text { Aging and Society: An Interdisciplinary Journal } \\
\text { Website: http://AgingAndSociety.com/journal/ }\end{array}$ & $\begin{array}{c}\text { ARTS } \\
\text { The International Journal of the Arts in Society. } \\
\text { Website: www.Arts-Journal.com }\end{array}$ \\
\hline $\begin{array}{c}\text { BOOK } \\
\text { The International Journal of the Book } \\
\text { Website: www.Book-Journal.com }\end{array}$ & $\begin{array}{c}\text { CLIMATE CHANGE } \\
\text { The International Journal of Climate Change: } \\
\text { Impacts and Responses } \\
\text { Website: www.Climate-Journal.com }\end{array}$ \\
\hline $\begin{array}{c}\text { CONSTRUCTED ENVIRONMENT } \\
\text { The International Journal of the } \\
\text { Constructed Environment } \\
\text { Website: } \text { www.ConstructedEnvironment.com/journal }\end{array}$ & $\begin{array}{c}\text { DESIGN } \\
\text { Design Principles and Practices: } \\
\text { An International Journal } \\
\text { Website: www.Design-Journal.com }\end{array}$ \\
\hline $\begin{array}{c}\text { DIVERSITY } \\
\text { The International Journal of Diversity in } \\
\text { Organizations, Communities and Nations } \\
\text { Website: www.Diversity-Journal.com }\end{array}$ & $\begin{array}{l}\text { FOOD } \\
\text { Food Studies: An Interdisciplinary Journal } \\
\text { Website: http://Food-Studies.com/journal/ }\end{array}$ \\
\hline $\begin{array}{c}\text { GLOBAL STUDIES } \\
\text { The Global Studies Journal } \\
\text { Website: www.GlobalStudiesJournal.com }\end{array}$ & $\begin{array}{c}\text { HEALTH } \\
\text { The International Journal of Health, } \\
\text { Wellness and Society } \\
\text { Website: www.HealthandSociety.com/journal }\end{array}$ \\
\hline $\begin{array}{c}\text { HUMANITIES } \\
\text { The International Journal of the Humanities } \\
\text { Website: www. Humanities-Journal.com }\end{array}$ & $\begin{array}{c}\text { IMAGE } \\
\text { The International Journal of the Image } \\
\text { Website: www.Onthelmage.com/journal }\end{array}$ \\
\hline $\begin{array}{l}\text { LEARNING } \\
\text { The International Journal of Learning. } \\
\text { Website: www.Learning-Journal.com }\end{array}$ & $\begin{array}{c}\text { MANAGEMENT } \\
\text { The International Journal of Knowledge, } \\
\text { Culture and Change Management. } \\
\text { Website: www.Management-Journal.com }\end{array}$ \\
\hline $\begin{array}{c}\text { MUSEUM } \\
\text { The International Journal of the Inclusive Museum } \\
\text { Website: www.Museum-Journal.com }\end{array}$ & $\begin{array}{c}\text { RELIGION AND SPIRITUALITY } \\
\text { The International Journal of Religion and } \\
\text { Spirituality in Society } \\
\text { Website: www.Religion-Journal.com }\end{array}$ \\
\hline $\begin{array}{c}\text { SCIENCE IN SOCIETY } \\
\text { The International Journal of Science in Society } \\
\text { Website: www.ScienceinSocietyJournal.com }\end{array}$ & $\begin{array}{c}\text { SOCIAL SCIENCES } \\
\text { The International Journal of Interdisciplinary } \\
\text { Social Sciences } \\
\text { Website: www.SocialSciences-Journal.com }\end{array}$ \\
\hline $\begin{array}{c}\text { SPACES AND FLOWS } \\
\text { Spaces and Flows: An International Journal of } \\
\text { Urban and ExtraUrban Studies } \\
\text { Website: www.SpacesJournal.com }\end{array}$ & $\begin{array}{c}\text { SPORT AND SOCIETY } \\
\text { The International Journal of Sport and Society } \\
\text { Website: www.sportandsociety.com/journal }\end{array}$ \\
\hline $\begin{array}{c}\text { SUSTAINABILITY } \\
\text { The International Journal of Environmental, Cultural, } \\
\text { Economic and Social Sustainability } \\
\text { Website: www.Sustainability-Journal.com }\end{array}$ & $\begin{array}{c}\text { TECHNOLOGY } \\
\text { The International Journal of Technology, } \\
\text { Knowledge and Society } \\
\text { Website: www.Technology-Journal.com }\end{array}$ \\
\hline $\begin{array}{c}\text { UBIQUITOUS LEARNING } \\
\text { Ubiquitous Learning: An International Journal } \\
\text { Website: www.ubi-learn.com/journal/ }\end{array}$ & $\begin{array}{l}\text { UNIVERSITIES } \\
\text { Journal of the World Universities Forum } \\
\text { Website: www.Universities-Journal.com }\end{array}$ \\
\hline
\end{tabular}

